\title{
A CASE SERIES OF DIAPHRAGMATIC INJURIES IN OUR INSTITUTE
}

\author{
Sankar Lingam¹, Sabrena2, Alex Franklin³, Sathish Kailasam4 ${ }^{4}$ Arikrishnan Vaithiswaran ${ }^{5}$ \\ ${ }^{1}$ Assistant Professor, Department of General Surgery, Chengalpattu Medical College and Hospital. \\ ${ }^{2}$ Assistant Professor, Department of General Surgery, Chengalpattu Medical College and Hospital. \\ 3Junior Resident, Department of General Surgery, Chengalpattu Medical College and Hospital. \\ 4Junior Resident, Department of General Surgery, Chengalpattu Medical College and Hospital. \\ 5junior Resident, Department of General Surgery, Chengalpattu Medical College and Hospital.
}

\section{ABSTRACT}

\section{BACKGROUND}

Diaphragmatic rupture is a life-threatening condition. Diaphragmatic injuries are quite uncommon and often result from either blunt or penetrating trauma. Diaphragmatic ruptures are usually associated with abdominal trauma; however, it can occur in isolation. Acute traumatic rupture of the diaphragm may go unnoticed and there is often a delay between the injury and the diagnosis. A comprehensive literature search was performed using the terms "delayed presentation of post-traumatic diaphragmatic rupture" and "delayed diaphragmatic rupture." The diagnostic and management challenges encountered are discussed together with strategies for dealing with them. We have focussed on mechanism of injury, duration, presentation and site of injury, visceral herniation, investigations and different approaches for repair. We intend to stress on the importance of delay in presentation of diaphragmatic rupture and to provide a review on the available investigations and treatment methods. The enclosed case report also emphasizes on the delayed presentation, diagnostic challenges and the advantages of laparoscopic repair of delayed diaphragmatic rupture. $1,2,3$

\section{METHODS}

A case series of traumatic diaphragmatic hernia and its management.

\section{RESULTS}

Diaphragmatic injuries account for less than 5\% of blunt injury abdomen, in this series we are publishing a series of 4 cases of diaphragmatic hernia secondary to trauma that we encountered during a 1-year period. 4,5

\section{CONCLUSION}

A knowledge of diaphragmatic hernia is essential for both the physician and the surgeon in atypical abdominal and respiratory discomfort, especially when there is history of trauma. This hernia is amenable to correction by minimal access surgery and requires a prompt diagnosis aided by a high index of suspicion.

\section{KEYWORDS}

Trauma, Diaphragm, Hernia.

HOW TO CITE THIS ARTICLE: Lingam S, Sabrena, Franklin A, et al. A case series of diaphragmatic injuries in our institute. J. Evolution Med. Dent. Sci. 2016;5(51):3255-3259, DOI: 10.14260/jemds/2016/756

\section{INTRODUCTION}

Diaphragmatic injuries are relatively rare; it is seen in less than $5 \%$ of blunt abdominal injuries. Both blunt and penetrating injuries can cause diaphragmatic injuries. First described by Sennertus in 1541. First repaired by Riolfi in 1886. First large series was published in 1951 by carter. In this series, we are publishing 4 cases of diaphragmatic injuries due to trauma that we encountered in a 1 year period.

\section{Review of Literature}

A PubMed search was conducted using the terms "delayed presentation of post-traumatic diaphragmatic rupture" and

Financial or Other, Competing Interest: None.

Submission 11-05-2016, Peer Review 04-06-2016,

Acceptance 11-06-2016, Published 25-06-2016.

Corresponding Author:

Dr. Sankar Lingam,

Assistant Professor,

Department of General Surgery,

Chengalpattu Medical College and Hospital,

Chengalpattu.

E-mail: kcpsankar@gmail.com

DOI: $10.14260 /$ jemds $/ 2016 / 756$ "delayed diaphragmatic rupture." Although quite a few articles were cited the details of presentation, investigations and treatment discussed in each of these were not identical, accounting for the variation in the data presented below. Late presentation of diaphragmatic rupture is often a result of herniation of abdominal contents into the thorax.6,7,8,9 Sudden increase in the intra-abdominal pressure may cause a diaphragmatic tear and visceral herniation. The incidence of diaphragmatic ruptures after thoraco-abdominal traumas is $0.8-5 \%$ and up to $30 \%$ diaphragmatic hernias present late. Diaphragmatic, lumbar and extra-thoracic hernias are well described complications of blunt trauma. Incorrect interpretation of the X-ray or only intermittent hernial symptoms are frequent reasons for incorrect diagnosis.

\footnotetext{
Mechanism of Injury

Diaphragmatic rupture with abdominal organ herniation was first described by Sennertus in 1541. Diaphragmatic injury is a recognised consequence of high velocity blunt and penetrating trauma to the abdomen and chest rather than from a trivial fall. These patients usually have multisystem injuries because of the large force required to rupture the
} 
diaphragm. Blunt trauma to the abdomen increases the transdiaphragmatic pressure gradient between the abdominal compartment and the thorax. This causes shearing of a stretched membrane and avulsion of the diaphragm from its points of attachments due to sudden increase in intraabdominal pressure, transmitted through the viscera.4,8,9 Delay in presentation of a diaphragmatic hernia could be explained by various different hypotheses. Delayed rupture of a devitalised diaphragmatic muscle may occur several days after the initial injury. This is best exemplified in the case report of bilateral diaphragmatic rupture, where the left diaphragmatic rupture was identified 24 hours after the motor vehicle accident and the right diaphragm which was explored at the initial laparotomy, manifested 10 days later. Intraoperative findings at the right thoracotomy revealed thin, inflamed diaphragm with necrotic muscle. The devitalised diaphragmatic muscle continues as a barrier until the inflammatory process weakens it. Extubation precipitates this phenomenon when the intrathoracic pressure becomes negative. $10,11,12,13$ However, the more likely explanation is a possible delayed detection assuming that the diaphragmatic defect occurring with injury manifests only when herniation occurs. Traumatic diaphragmatic hernia is a frequently missed diagnosis and there is commonly a delay between trauma and diagnosis. $14,15,16,17,18$

\section{Duration before Presentation}

Grimes in 1974 described the 3 phases of the rupture of the diaphragm. The acute phase is at the time of the injury to the diaphragm. The delayed phase is associated with transient herniation of the viscera, thus accounting for absence or intermittent non-specific symptoms. The obstruction phase signifies complication of a long-standing herniation, manifesting as obstruction, strangulation and rupture. The systematic review of the literature suggests one case being reported at 24 hours following trauma, 1 case each on Day 9, Day 10 and Day 11 following trauma. Two cases have been reported 6 months following the trauma while 1 case each had been reported 12 months, 18 months and 24 months following trauma. Two cases have been reported at 5 years, 1 case each at 8 years, 10 years, 20 years, 28 years, 40 years and 50 years. ${ }^{19}$

\section{Presenting Symptom}

Due to co-existing injuries and the silent nature of diaphragmatic ruptures, the diagnosis can sometimes be missed in the acute phase and may present later on with obstructive symptoms due to incarcerated organs in the diaphragmatic defect or eventual strangulation. Patients present with non-specific symptoms and may complain of chest pain, abdominal pain, dyspnoea, tachypnoea and cough. ${ }^{20,21,22,23}$ A high index of suspicion together with the knowledge of the mechanism of trauma is the key factor for the correct diagnosis. $24,25,26$ Our literature review confirmed cases presenting acutely with haemodynamic instability with abdominal pain some cases were reported to be asymptomatic diaphragmatic hernias. Respiratory distress was the presenting feature in some cases. Abdominal pain was the presenting feature in few cases. The pathophysiology was intestinal obstruction, pneumopericarditis, tension faecopneumothorax. There is report of one case presenting with haematemesis and melena. ${ }^{27,28}$

\section{Site of Rupture}

Although autopsy studies have revealed equal incidence of right and left diaphragmatic ruptures, ante-mortem study reports suggest $88-95 \%$ of diaphragmatic ruptures occurred on the left side. Right sided ruptures are associated with high mortality and morbidity and thus the underdiagnosis of right sided injuries may be due to greater pre-hospital mortality. Right sided tears are significantly less likely than left sided tears, because of the protective effect of the liver. This could also be explained by better visualisation of the left diaphragm on diagnostic laparoscopy, but restricted visualisation of the right diaphragm. The systematic review of literature has confirmed 27 cases of left sided rupture and 13 cases of right sided rupture were reported. The rarely reported sites include 1 central diaphragmatic hernia, 2 bilateral and 1 transdiaphragmatic intercostal hernia. The systematic review of literature also confirmed intra-abdominal and retroperitoneal contents in the hernia sac. ${ }^{29}$

\section{Case 1}

A 60 yr. old male pt admitted in June 2014 with complaints of dyspepsia for 1 month. H/o RTA +6 mths back he was initially managed outside. UGI scopy done outside was suggestive of gastric outlet obstruction, hence referred here for further treatment.

O/E: conscious oriented, PR 84/min, BP: 120/70 mmHg, CVS: S1 S2+, RS: NVBS+. Air entry diminished in left hemithorax, Bowel sounds + in left lower thorax. P/A: Scaphoid, soft, BS+.

CXR: Showed elevated left dome of diaphragm, CT Abdomen: Showed diaphragmatic hernia due to defect in left dome of diaphragm with herniation of stomach and small bowel into the pleural cavity.

Pt underwent laparotomy, intraop there was a $5 * 4 \mathrm{~cm}$ defect in the left dome of diaphragm with herniation of stomach and bowel, the contents were reduced and defect closed with 1 prolene using Vypro mesh. Left ICD inserted intraop, pt recovered well.

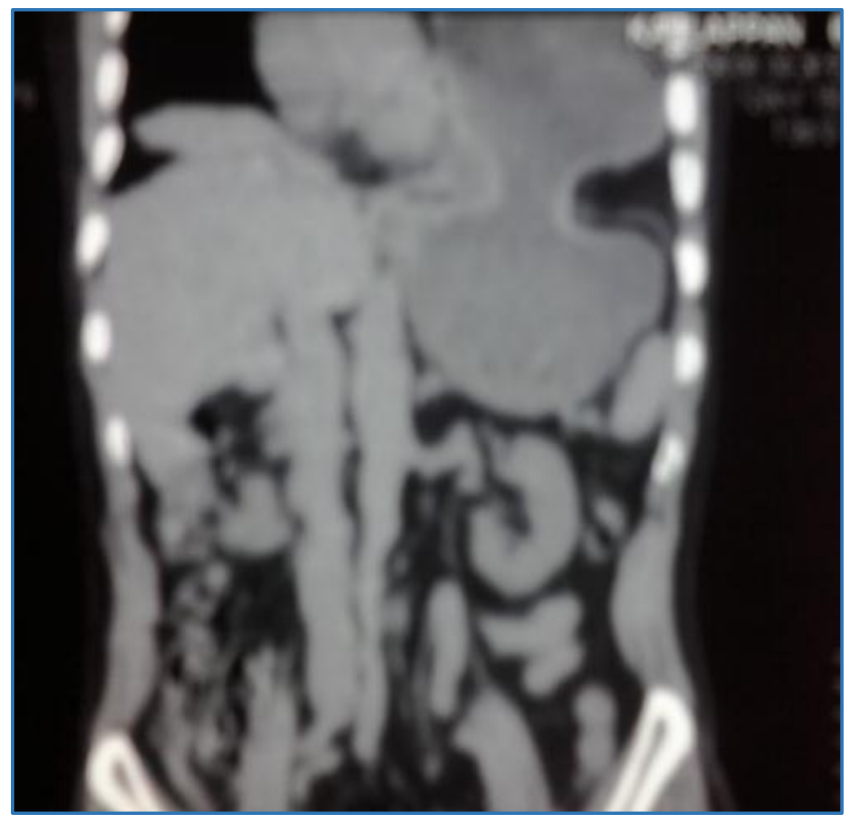

Fig. 1: CT Abdomen showing Herniation of Stomach 


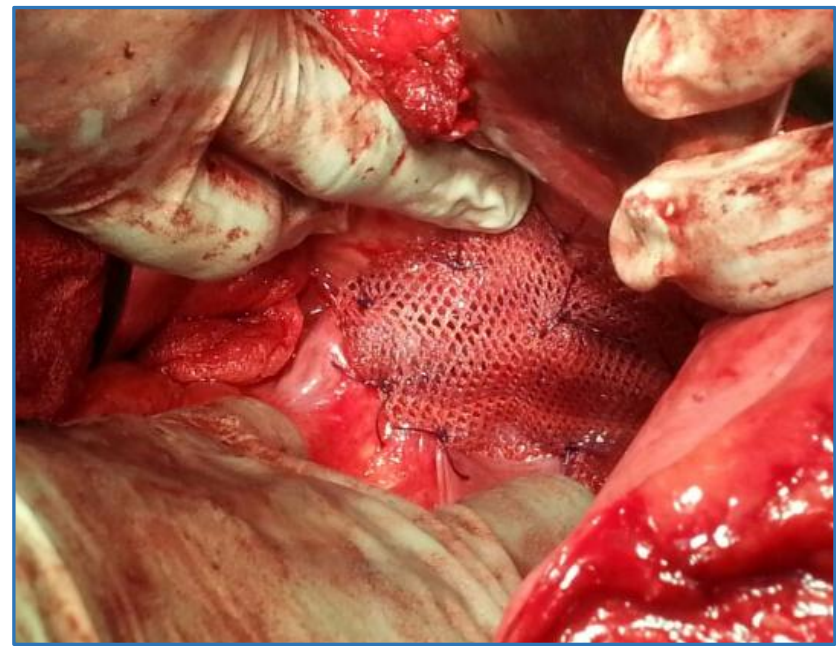

Fig. 2: Intraop Picture showing Mesh Repair

\section{Case 2}

A 26 yr. old male pt. admitted with alleged h/o assault with knife by one known person 1 day back. Wound was sutured outside. O/E: pt conscious oriented, PR: 86/min, BP: 110/70 mmHg. RS: NVBS+, air entry decreased in left base. CVS: S1 S2+, P/A: soft, diffuse tenderness +, guarding + in left hypochondrium and epigastrium. LE: $3 \mathrm{~cm}$ sutured wound present over left lower chest in the infra-axillary region.

CXR: Lt haemopneumothorax, CT: Lt haemopneumothorax with pneumoperitoneum and free fluid in pelvis. Intraop: $5 * 2$ $\mathrm{cm}$ defect in left dome of diaphragm with $2 * 1 \mathrm{~cm}$ gastric tear with herniation of omentum into the pleural cavity. Contents reduced and defect closed with 1 prolene primary closure of Gastric tear done. Lt ICD inserted, pt. recovered well.

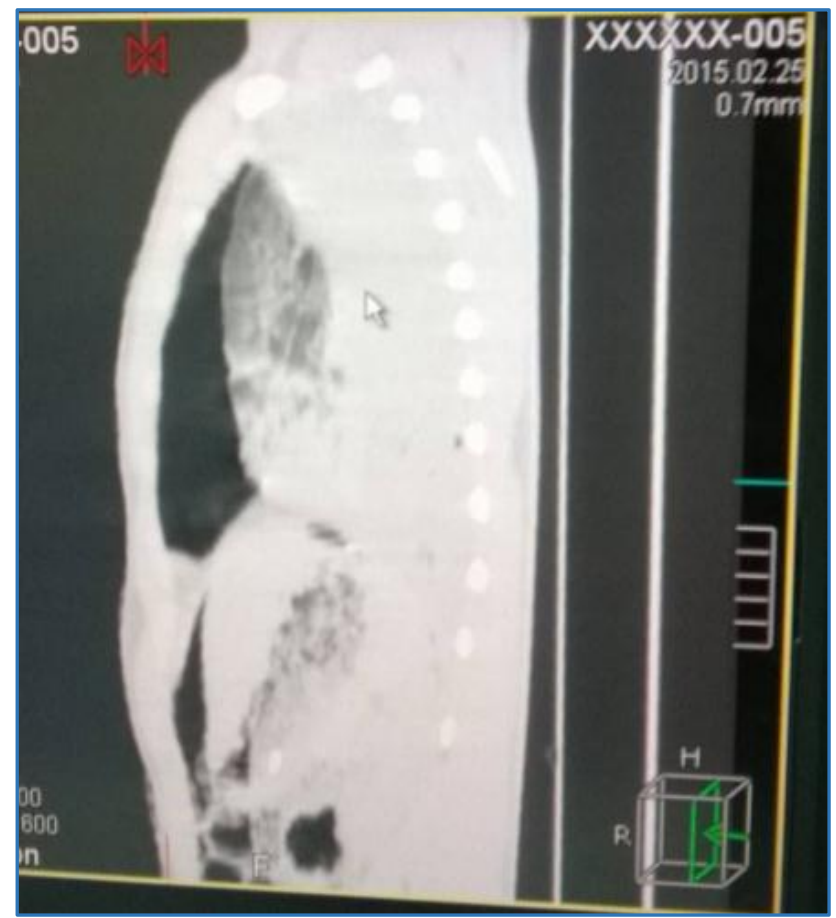

Fig. 1: CT Abdomen showing Pneumothorax with Pneumoperitoneum

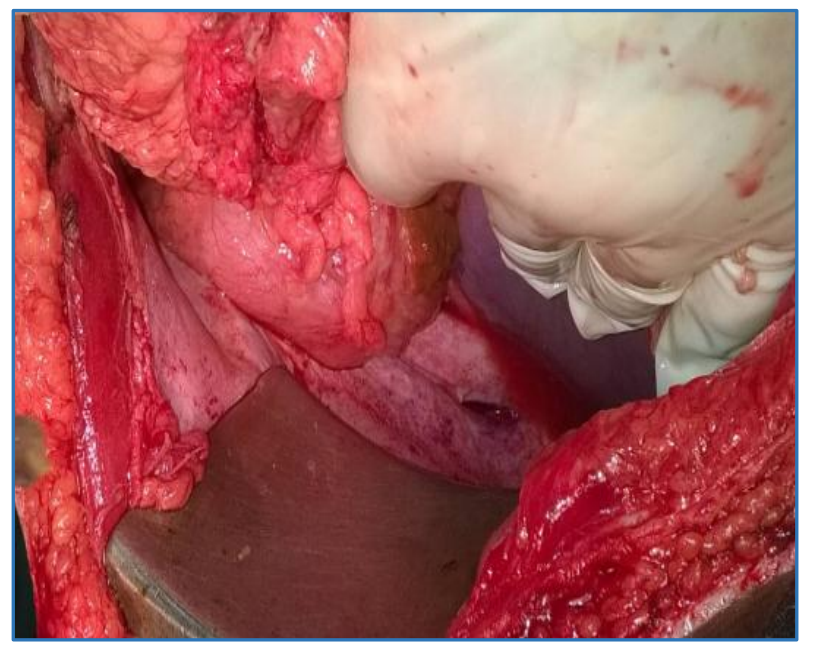

Fig. 2: Intraop Picture showing Defect

Case 3

A 35 yr. old male pt admitted with alleged H/o assault by one known person using knife 4 hrs. back. O/E: Pt conscious oriented, PR: $84 / \mathrm{min}, \mathrm{BP}$ : 120/70 mmHg. CVS: S1 S2+, RS: NVBS+ BAE, P/A: Soft, tenderness + over Lt hypochondrium, Bs+. LE: $2 \mathrm{~cm}$ sutured wound over left lower chest in infraaxillary region.

CXR: NAD. CT Abdomen: Pneumoperitoneum with free fluid in pelvis. Pt was taken up for laparotomy intraop: $3 * 1 \mathrm{~cm}$ defect in left dome of diaphragm with a $2 * 1 \mathrm{~cm}$ tear in descending colon. Primary closure of diaphragmatic defect was done using 1 prolene. Primary closure of descending colon tear done, Lt ICD inserted, pt recovered well.

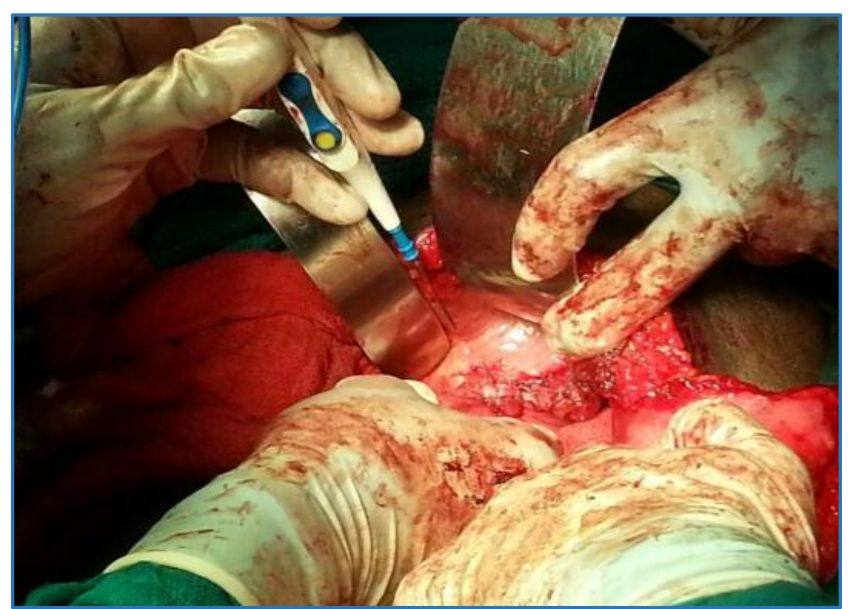

Fig. 3: Intraop Picture showing Repair of Defect

Case 4

A 30 yr. old male pt admitted with alleged H/o RTA 0/E: PR: 82/min, BP: 110/70 mmHg, CVS: S1S2+, RS; NVBS+BAE. P/A: Soft, tenderness present over suprapubic region. CNS: PERL+.

CXR: NAD. X-Ray Pelvis: Fracture B/L inferior pubic rami. Pt developed respiratory distress on day 2. CT Chest: Left sided diaphragmatic hernia with haemothorax. Pt was taken up for laparotomy intraop: $10 * 3 \mathrm{~cm}$ defect in left dome of diaphragm with herniation of stomach and small intestine. Complete transection of terminal ileum $15 \mathrm{~cm}$ from IC junction. After reduction of contents, Lt ICD was inserted, defect in diaphragm closed with 1 prolene. Resection anastomosis of terminal ileum done. Pt recovered well. 


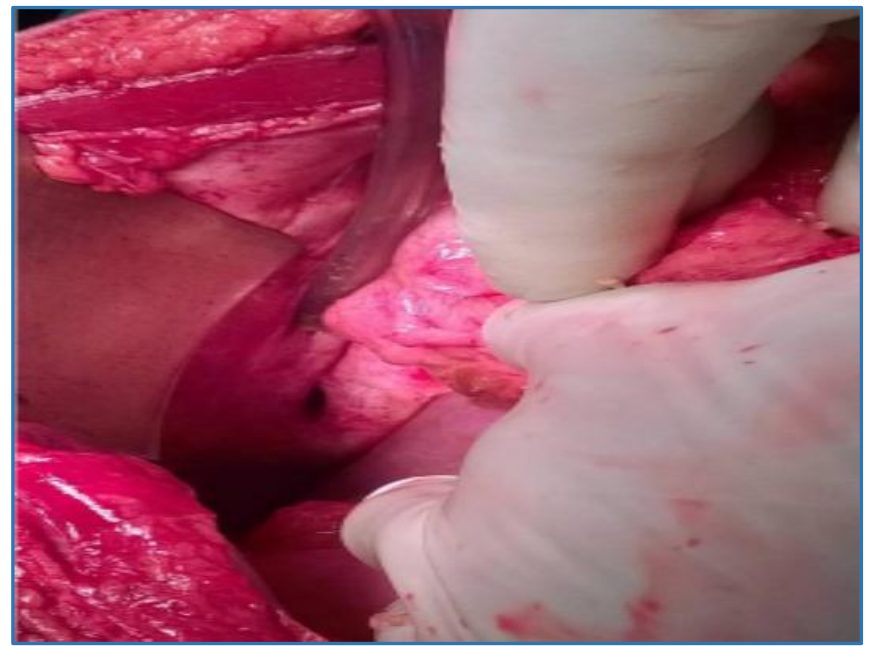

Fig. 4: Intraop Picture showing Defect with Herniation

\section{DISCUSSION}

80-90\% of diaphragmatic injuries are caused by RTA's. Left sided injuries are more common than right, but right sided injuries are more severe. Injury occurs due to pressure difference between pleural and peritoneal cavity. Blunt injuries produce large radial tears, while penetrating injuries produce linear defects. In penetrating injuries, diaphragmatic injuries should be suspected if entry wound is below the level of nipple or scapula.

Diagnosis may be missed in $50-60 \%$ of pts initially. They may present in the acute phase with respiratory distress. There may be bowel sounds in the chest on auscultation. In the latent phase, pt may present with symptoms due to bowel herniation. In the late phase, pt may present with bowel obstruction or tension pneumothorax.

\section{INVESTIGATIONS}

CXR-may show herniated bowel loops or Ryles Tube in thorax. CT scan-especially helical CT is highly effective in detecting diaphragmatic injuries. MRI is very useful in detection of small defects in stable pts. Videothoracoscopy-can be used to detect even small asymptomatic defects.

\section{TREATMENT}

All diaphragmatic defects need to be repaired, as due to pressure difference the defect never heals and may lead to symptomatic hernia later. Defects especially large ones in the central region will need mesh repair. Peripheral defects can be closed primarily using non-absorbable sutures.

\section{CONCLUSION}

A knowledge of diaphragmatic hernia is essential for both the physician and the surgeon in atypical abdominal and respiratory discomfort, especially when there is history of trauma. This hernia is amenable to correction by minimal access surgery and requires a prompt diagnosis aided by a high index of suspicion.

\section{SUMMARY}

A high clinical index of suspicion is needed to diagnose and effectively manage diaphragmatic rupture even with a remote history of high-velocity injury. This is particularly true when other signs of severe trauma are present such as multiple rib fracture, lacerations of liver and spleen or a history of deceleration injury. We have emphasised that when tension pneumothorax and diaphragmatic hernia coexist, the contents of the visceral sac may be completely reduced and the hernia is thus masked. The drainage of a considerable amount of serous fluid in addition to air, in the presence of tension pneumothorax may suggest a communication with the peritoneal cavity. We do recommend that a high index of suspicion should be kept in mind, while dealing with patients who do get readmitted with upper abdominal symptoms whenever there is a history of trauma or blunt injury regardless of the fact whether it was a few days ago or many years ago. We consider laparoscopic repair to be a suitable and safe procedure for treatment of diaphragmatic rupture.

\section{REFERENCES}

1. Shreck GL, Toalson TW. Delayed presentation of traumatic rupture of the diaphragm. J Okla State Medical Association 2003;96(4):181-3.

2. Disler DG, Deluca SA. Traumatic rupture of the diaphragm and herniation of the liver. Am Fam Physician 1992;46(2):453-6.

3. Rossetti G, Brusciano L, Maffetone V, et al. Giant right post-traumatic diaphragmatic hernia: laparoscopic repair without a mesh. Chir Ital 2005;57(2):243-6.

4. Pappas-Gogos G, Karfis EA, Kakadellis J, et al. Intrathoracic cancer of the splenic flexure. Hernia 2007;11(3):257-9.

5. Crandall M, Popowich D, Shapiro M, et al. Posttraumatic hernias: historical overview and review of literature. Am Surg 2007;73(9):845-50.

6. DeBlasio R, Maione P, Avallone U, et al. Late posttraumatic diaphragmatic hernia. A clinical case report. Minerva Chir 1994;49(5):481-7.

7. Christie DB, Chapman J, Wynne JL, et al. Delayed right sided diaphragmatic rupture and chronic herniation of unusual abdominal contents. Journal of the American College of Surgeons 2007;204(1):176.

8. Goh BK, Wong AS, Tay KH, et al. Delayed presentation of a patient with a ruptured diaphragm complicated by gastric incarceration and perforation after apparently minor blunt trauma. Canadian Journal of Emergency Medicine 2004;6(4):277-80.

9. Meyers BF, McCabe CJ. Traumatic diaphragmatic hernia. Occult marker of serious injury. Ann Surg 1993;218(6):783-90.

10. Sangster G, Ventura VP, Carbo A, et al. Diaphragmatic rupture: a frequently missed injury in blunt thoracoabdominal trauma patients. Emerg Radiol 2007;13(5):225-30.

11. Walchalk LR, Stanfield SC. Delayed presentation of traumatic diaphragmatic rupture. Journal of Emergency Medicine in press 2008.

12. Sirbu H, Busch T, Spillner J, et al. Late bilateral diaphragmatic rupture: challenging diagnostic and surgical repair. Hernia 2005;9(1):90-2.

13. Faul JL. Diaphragmatic rupture presenting forty years after injury. Injury 1998;29(6):479-80.

14. Grimes OF. Traumatic injuries of the diaphragm. Diaphragmatic hernia. Am J Surg 1974;128(2):175-81.

15. Launey Y, Geeraerts T, Martin L, et al. Delayed traumatic right diaphragmatic rupture. Anaesth Analg 2007;104(1):224-5. 
16. Kelly J, Condon ET, Kirwan WO, et al. Post-traumatic tension faecopneumothorax in a young male: case report. World Journal Emergency Surgery 2008;3:20.

17. Pojarliev T, Tzvetkov I, Blagov J, et al. Laparoscopic repair of traumatic rupture of the left diaphragm cupola with prosthetic mesh. Surg Endosc 2003;17(4):660.

18. Al-Mashat F, Sibiany A, Kensarah A, et al. Delayed presentation of traumatic diaphragmatic rupture. Indian J Chest Dis Allied Sci 2002;44(2):121-4.

19. Ramdass MJ, Kamal S, Paice A, et al. Traumatic diaphragmatic herniation presenting as delayed tension faecopneumothorax. Emergency Medical Journal 2006;23(10):e54.

20. Reina A, Vidana E, Soriano $P$, et al. Traumatic intrapericardial diaphragmatic hernia: case report and literature review. Injury 2001;32(2):153-6.

21. Kafih M, Boufettal R. A late post traumatic diaphragmatic hernia revealed by a tension fecopneumothorax (a case report). Rev Pneumol Clinic 2009;65(1):23-6.

22. Hariharan D, Singhal R, Kinra S, et al. Post traumatic intra thoracic spleen presenting with upper GI bleed!-a case report. BMC Gastroenterol 2006;6:38.
23. Singh S, Kalan MM, Moreyra CE, et al. Diaphragmatic rupture presenting 50 years after the traumatic event. J Trauma 2000;49(1):156-9.

24. Ruiz-Tovar J, Gracia PC, Castineiras MV, et al. Post trauma diaphragmatic hernia. Rev Gastroenterol Peru 2008;28(3):244-7.

25. Mintz Y, Easter DW, Izhar U, et al. Minimally invasive procedures for diagnosis of traumatic right diaphragmatic tears: a method for correct diagnosis in selected patients. Am Surg 2007;73(4):388-92.

26. Letoquart JP, Fasquel JL, L'Huillier JP, et al. Gastropericardial fistula. Review of literature apropos of an original case. J Chir (Paris) 1990;127(1):6-12.

27. Warren O, Kinross J, Paraskeva P, et al. Emergency laparoscopy-current best practice. World J Emerg Surg 2006; $1: 24$.

28. How C, Tee A, Quah J. Delayed presentation of gastrothorax masquerading as pneumothorax. Prim Care Respir J 2007;16(1):54-6.

29. Leoncini G, Iurilli L, Lupi $P$, et al. Intrathoracic perforation of the gastric fundus as a late complication of an unknown post-traumatic rupture of the diaphragm. G Chir 1998;19(5):235-8. 